\title{
Urinary Tract Infections: Leading Initiatives in Selecting Empiric Outpatient Treatment (UTILISE)
}

\author{
Eric Landry, Linda Sulz, Ali Bell, Lane Rathgeber, and Heather Balogh
}

\begin{abstract}
Background: Overuse of fluoroquinolone antibiotics is associated with outbreaks of methicillin-resistant Staphylococcus aureus and of Clostridium difficile-associated diarrhea and increasing resistance in gram-negative organisms. Over the past decade, resistance of Escherichia coli to ciprofloxacin has increased in the Regina Qu'Appelle Health Region. In August 2011, an exploratory audit of the Regina General Hospital (RGH) emergency department showed that $20 \%$ of new antibiotic orders were for fluoroquinolones, and $60 \%$ of these new fluoroquinolone orders were for ciprofloxacin. It was postulated that ciprofloxacin was predominantly prescribed for outpatients with urinary tract infection.
\end{abstract}

Objective: To develop, implement, and evaluate a best-practice algorithm for the empiric treatment of uncomplicated urinary tract infection in the RGH emergency department, as part of an educational initiative for emergency physicians.

Methods: A literature review was conducted and local antibiogram data were analyzed to establish a best-practice algorithm for treatment of uncomplicated urinary tract infection in outpatients seen in the emergency department. A chart review was conducted from January to March 2011 to establish a baseline of empiric antibiotic use. An educational strategy targeting emergency physicians described changes in antibiotic resistance patterns in the health region, principles of antimicrobial stewardship, drivers of resistance, and the results of a literature review of best practice for urinary tract infection in outpatients. A post-intervention audit was conducted from January to March 2012 to determine changes in practice.

Results: Comparison of results from the post-intervention audit with baseline data showed that adherence to best practice increased significantly, from $41 \%$ (39/96) before the intervention to 66\% (50/76) after the intervention (odds ratio [OR] 2.81, 95\% confidence interval [CI] $1.51-5.25 ; p<0.001)$. There was also a significant change in overall antibiotic selection (OR 0.25, 95\% CI $0.11-0.58$; $p<0.001$ ). Further analysis suggested that this significant change was driven by a decrease in use of ciprofloxacin, from $32 \%(31 / 96)$ to $11 \%(8 / 76)$.

Conclusion: Creation of a best-practice algorithm and education focused on emergency physicians significantly increased adherence to best practice and optimized antibiotic prescribing for outpatients

\section{RÉSUMÉ}

Contexte : Lutilisation abusive d'antibiotiques de la famille des fluoroquinolones est associée à des éclosions de Staphylococcus aureus résistant à la méthicilline et de diarrhée provoquée par le Clostridium difficile ainsi qu'à une augmentation de la résistance des bactéries à Gram négatif. Au cours de la dernière décennie, la résistance d'Escherichia coli à la ciprofloxacine a augmenté dans la régie régionale de la santé de Regina Qu’Appelle. En août 2011, une vérification préliminaire du service des urgences de l'Hôpital général de Régina (HGR) a montré que $20 \%$ des nouvelles ordonnances d'antibiotiques étaient pour des fluoroquinolones et que $60 \%$ de ces ordonnances étaient pour de la ciprofloxacine. On a émis l'hypothèse selon laquelle on prescrivait principalement la ciprofloxacine aux patients externes atteints d'une infection urinaire.

Objectif : Élaborer, mettre en place et évaluer un algorithme des meilleures pratiques pour le traitement empirique d'infections urinaires non compliquées au service des urgences de l'HGR dans le cadre d'une initiative de formation destinée aux urgentologues.

Méthodes : Une revue de la littérature a été menée et les données locales d'antibiogrammes ont été analysées afin de définir un algorithme des meilleures pratiques destiné au traitement des infections urinaires non compliquées chez les patients externes rencontrés au service des urgences. Une analyse des dossiers médicaux a été effectuée de janvier à mars 2011 dans le but d'établir le traitement antibiotique empirique de référence. Une stratégie de formation destinée aux urgentologues décrivait : les changements dans les profils de résistance aux antibiotiques au sein de la régie régionale de la santé, les principes d'une gestion responsable des antimicrobiens, ainsi que les facteurs de résistance. Elle contenait aussi une revue de la littérature des meilleures pratiques pour traiter les infections urinaires chez les patients externes. Une vérification post-intervention a été menée de janvier à mars 2012 afin de déterminer les changements dans la pratique.

Résultats : Une comparaison entre la vérification post-intervention et les données de référence a montré une augmentation significative de l'observance des meilleures pratiques, qui est passée de $41 \%$ (39/96) avant l'intervention à $66 \%(50 / 76)$ après l'intervention (risque relatif approché [RRA] de 2,81, intervalle de confiance [IC] à $95 \%$ de 1,51-5,25; $p<0,001)$. On a aussi observé un changement significatif dans les habitudes de choix d'antibiotiques (RRA de 0,25 , IC à $95 \%$ de $0,11-0,58$; $p<0,001)$. D'après d'autres analyses, ce changement significatif a été causé par une baisse de l'utilisation de la ciprofloxacine, qui est passée de $32 \%$ $(31 / 96)$ à $11 \%(8 / 76)$. 
with uncomplicated urinary tract infection by limiting overuse of fluoroquinolones, primarily ciprofloxacin.

Keywords: urinary tract infection, emergency department, empiric treatment, Escherichia coli resistance, fluoroquinolones

Can J Hosp Pharm. 2014;67(2):116-25
Conclusion : L'élaboration d'un algorithme des meilleures pratiques ainsi qu'une formation destinée aux urgentologues ont permis d'augmenter de manière significative l'observance des meilleures pratiques. Elles ont aussi permis d'optimiser la prescription d'antibiotiques aux patients externes atteints d'une infection urinaire non compliquée en réduisant l'utilisation abusive des fluoroquinolones, notamment celle de la ciprofloxacine.

Mots clés : infection urinaire, service des urgences, traitement empirique, résistance de l'E. coli, fluoroquinolones

[Traduction par l'éditeur]

\section{INTRODUCTION}

$\mathrm{D}$ espite evidence that misuse of antimicrobials is directly linked to increased organism resistance, increased costs of health care delivery, and negative effects on morbidity and mortality, rates of resistance continue to rise worldwide, ${ }^{1,2}$ implying that misuse continues. This trend is compounded by the current paucity of novel antibiotics to combat the more virulent organisms anticipated in the near future. ${ }^{3,4}$

Fluoroquinolones in particular continue to be implicated in antimicrobial resistance. ${ }^{5,6}$ With their wide spectrum of activity, convenient dosing, and good patient tolerability, fluoroquinolones have played an important role in the treatment of infectious disease since their introduction some decades ago. ${ }^{2.5,6}$ As prescribers' use of these drugs continues to rise, so too do concerns about increasing resistance to this class of antibiotics. ${ }^{6}$ In addition to the problem of resistance, fluoroquinolones often have unintended negative effects on other organisms, a phenomenon known as "collateral damage". ${ }^{6,7}$ Evidence of collateral damage associated with the use of fluoroquinolones includes correlation with outbreaks of infections due to methicillin-resistant Staphylococcus aureus and with Clostridium difficile-associated diarrhea, increasing resistance of gram-negative bacilli (e.g., Escherichia coli, Pseudomonas aeruginosa), and infection or colonization with multidrugresistant organisms. ${ }^{6-10}$ A significant contributor to collateral damage, and a driving force of increasing resistance, is thought to be the overuse of fluoroquinolones in the treatment of uncomplicated infections for which reliable, narrowerspectrum alternatives exist. A common example of such infections is uncomplicated urinary tract infection (UTI). ${ }^{2,7,11}$

E. coli is still the most frequent causative organism for UTIs, thought to be responsible for $75 \%$ to $95 \%$ of uncomplicated infections. ${ }^{7,12,13}$ It is also one of several organisms that are increasingly resistant to fluoroquinolones: a recent Canadian source ${ }^{14}$ reported E. coli resistance at between $10 \%$ and $15 \%$ in some areas of the country, and sources for other countries have reported resistance rates as high as $15 \%$ to $25 \% \cdot{ }^{12,15}$ In a study of changes in resistance to fluoroquinolones in 10 teaching hospitals across the United States, Zervos and others ${ }^{2}$ found that resistance of $E$. coli increased by a mean of $6.8 \%$ (range 0\%-16\%) between 1991 and 2000. More recently, WongBeringer and others ${ }^{6}$ reported an increase in resistance of $E$. coli to fluoroquinolones from $4 \%$ to $23 \%$ over the period 1997 to 2004 in a 525-bed teaching hospital in California. An increase of similar magnitude has recently been observed in the Regina Qu'Appelle Health Region (RQHR). A 2010/2011 RQHR pharmacy residency project, based in part on 2009/2010 antibiogram data, ${ }^{16}$ revealed that $E$. coli resistance to ciprofloxacin increased from $2 \%$ in 2000 to $13 \%$ (among inpatients) and 15\% (among outpatients) in 2010 (Fedor L, Sulz L, Bell A, Ruda L, Smycniuk A, Semchuk W. Improving fluoroquinolone use to minimize resistance: an antimicrobial stewardship pilot study [RESIST]; unpublished report). Antibiogram data for 2010/2011 revealed that sensitivity of E. coli to ciprofloxacin continued to decrease for urine isolates from both outpatients (from $90 \%$ to $88 \%$ ) and inpatients (from $85 \%$ to $82 \%$ ). ${ }^{17}$ This continued increase in resistance to fluoroquinolones confirmed the need for vigilant promotion of antimicrobial stewardship and validated the timeliness of the UTILISE study reported here.

In their case-control study examining risk factors for inappropriate use of fluoroquinolones, Lautenbach and others ${ }^{5}$ found that $25 \%$ of all antibiotics prescribed for outpatients seen in the emergency department were fluoroquinolones. They further reported that $81 \%$ of these prescriptions were deemed inappropriate. ${ }^{5}$ At the RQHR, a preliminary audit of antibiotic utilization was conducted in August 2011 using the pharmacy informatics system (GE Centricity). The findings indicated that, over a randomly selected period of 3 months (from November 2010 to January 2011), 481 new orders for fluoroquinolones were initiated in the RGH emergency department. Of these orders, which accounted for $20 \%$ of all new antibiotic orders, $60 \%$ were for ciprofloxacin.

It was believed that in a significant proportion of cases, ciprofloxacin was being inappropriately prescribed for 
outpatients with uncomplicated UTIs. It was postulated that within the RGH emergency department, an opportunity existed to reduce fluoroquinolone use by optimizing the prescribing of narrower-spectrum antimicrobials for the treatment of this type of infection.

In an effort to draw attention to and provide strategies for the prevention of antimicrobial resistance in hospitals, the Infectious Diseases Society of America (IDSA) and the Society for Healthcare Epidemiology of America (SHEA) have published several sets of guidelines focusing on antimicrobial stewardship since the 1980 s. ${ }^{1,18,19}$ Antimicrobial stewardship is a multifaceted approach to optimizing clinical outcomes for patients, while minimizing the emergence of resistance, through responsible utilization of antimicrobials.

Common antimicrobial principles often include initiation of broad-spectrum therapy, which is then narrowed once cultures and sensitivities are known. This step-down to narrower-spectrum therapy may be perceived as more difficult to accomplish for outpatients, in part because family practitioners may not be easily accessible for timely follow-up. The emergency department therefore represents an important environment for the establishment of a culture of antimicrobial stewardship. Objective 3.9 of the CSHP 2015 initiative of the Canadian Society of Hospital Pharmacists specifies that "pharmacists will be actively involved in medication- and vaccination-related infection control programs." ${ }^{20}$ This national initiative illustrates that pharmacists have an important role to play in promoting responsible utilization of antimicrobials. ${ }^{20}$

The guidelines of the IDSA and SHEA list several evidence-based strategies to promote antimicrobial stewardship, including prospective audits with intervention and feedback, formulary restriction, antimicrobial cycling, and education. Among these is the development of evidence-based practice guidelines, an approach that has been shown to improve antimicrobial utilization. ${ }^{1}$ The pharmacist-led study reported here focused on both education and the development of a practice guideline as strategies to implement this antimicrobial stewardship initiative.

The objective of this study was to develop, implement, and evaluate a best-practice algorithm for the empiric treatment of uncomplicated UTIs in the RGH emergency department, as part of an educational initiative for emergency physicians.

\section{METHODS}

This study was conceived and completed within the 1-year timeframe of a hospital pharmacy residency. It was set in the emergency department of an academic tertiary care centre with a census of 56000 patient visits in calendar year 2012. The Regina Qu'Appelle Health Region Research Ethics Board provided ethics approval for the study. The study design consisted of development and implementation of interventions to improve antibiotic utilization and performance of pre- and post-intervention retrospective chart audits to determine the effect of the interventions on adherence to best practice. The development of the study methods was led by the primary investigator, a hospital pharmacy resident (E.L.), in collaboration with the study stakeholders, consisting of the RQHR Director of Emergency Medicine, the hospital's emergency physicians, members of the RQHR Antimicrobial Utilization Committee (now the Regina Qu'Appelle Health Region Antimicrobial Stewardship Program) (L.S., L.R.), the RQHR medical microbiologist, and the RQHR Strategic Initiatives Pharmacy Manager (L.S.).

\section{Development of Best-Practice Algorithm}

The development of best practice was a multistep process beginning with an in-depth review of the literature. To identify current best practices for empiric treatment of uncomplicated UTIs, the primary investigator conducted a search of MEDLINE, International Pharmaceutical Abstracts, and PubMed databases from the year 2005 to the year 2011 inclusive; the cited references of identified articles were also reviewed. Only studies published in English were included. The following search terms were used: "urinary tract infection", "cystitis", "pyelonephritis", "empiric treatment", "fluoroquinolone", "emergency department", "outpatient", "antibiotic resistance", and "best practice". When discordance between articles existed, the authors deferred to the Canadian literature, and recommendations were weighted accordingly.

Broad consultation with physicians from the Infectious Diseases service and the emergency department, in conjunction with the literature review and a review of local antibiogram data, led to the development of a treatment selection tool (Appendix 1) and a best-practice algorithm (Appendix 2) (appendices available online at www.cjhp-online.ca/index.php/ cjhp/issue/view/101/showToc). The treatment selection tool was designed as an eye-catching quick reference, outlining the preferred antibiotic agents. The best-practice algorithm was a more detailed tool designed to help guide practitioners in selecting appropriate antibiotic therapy, beginning with choices based on type of infection (upper or lower UTI). The best-practice algorithm included additional treatment details not found in the treatment selection tool, such as suggested duration of therapy.

\section{Educational Intervention}

The primary investigator was invited to present at a monthly emergency department meeting in December 2011. Those in attendance were 17 of 30 full-time emergency physicians, the department head, and the nursing manager and nursing director (representing emergency nursing staff). The 
presentation covered information on antimicrobial stewardship, including the problems associated with fluoroquinolone overuse and antibiotic resistance, local RQHR resistance data, results of the literature review of best practice, findings of the baseline audit (as described in the next section), and presentation and discussion of the treatment selection tool and the best-practice algorithm (Appendices 1 and 2, available online at www.cjhp-online.ca/index.php/cjhp/issue/view/101/show Toc). Following the session, posters of best practice were displayed throughout the emergency department as a convenient point of reference for prescribers. A print version of the educational session was posted for several weeks on the educational bulletin board in the emergency department. All best-practice tools and the PowerPoint slides from the original presentation were made available on the department's intranet home page. A similar presentation was made to RGH staff pharmacists in February 2012. Presentation and poster materials were made available to the pharmacists who attended and were posted within the department.

\section{Pre-intervention Chart Audit}

A retrospective chart audit was performed by the primary investigator to establish a baseline of antibiotic use for empiric treatment of outpatients with uncomplicated UTI. For the purposes of this study, an uncomplicated case of UTI was defined as a case in which a patient presenting to the $\mathrm{RGH}$ emergency department was given a diagnosis of cystitis, pyelonephritis, urosepsis, or UTI but was not admitted to hospital (i.e., outpatients only). Patients were excluded if they met any of the following criteria: pregnancy, residence in a nursing home, indwelling catheter in situ, spinal cord injury, urinary tract abnormality or obstruction, or age less than 13 years.

For potential inclusion in the pre-intervention audit, patient visits from January to March 2011 were identified by the Health Information Management Services Department of RGH. Charts of patients meeting the inclusion criteria were reviewed for exclusion criteria, as listed above. A data collection form was used to gather information about demographic characteristics, diagnosis, antibiotics prescribed, results of culture and sensitivity testing, and antibiotic use within the previous 4 months (according to the Saskatchewan Drug Plan Pharmaceutical Information Program form in each patient's chart).

To assess adherence to defined best practice, specificity of diagnosis is required. Through consultation with the UTILISE Advisory Committee members (L.S., L.R., H.B.), it was decided to infer a diagnosis of upper UTI if any of the following common signs or symptoms were present in the assessments of either nurses or physicians: fever, flank or lower back pain, right or left upper quadrant pain, nausea, vomiting, or chills. Similarly, a diagnosis of lower UTI was inferred if any of the following signs or symptoms were present: frequency, urgency, dysuria, or suprapubic pain. For cases that remained unspecified despite these strategies of inference, a default diagnosis of upper UTI was inferred. This approach was thought to be prudent, as patients with a diagnosis of UTI without classic signs and symptoms may be more likely to experience vague, constitutional symptoms consistent with a systemic infection. The primary investigator evaluated adherence to best practice using Appendix 2, according to the assessment process outlined in Figure 1. The study coauthors were consulted in the event of any uncertainty or discrepancies.

\section{Post-intervention Chart Audit}

Patient records from the same 3-month period the following year (January to March 2012) were scrutinized for inclusion in the post-intervention audit. A second chart review was completed, as described above for the pre-intervention audit, including the approach to inferred diagnosis of upper versus lower UTI and the assessment of adherence to best practice.

\section{Statistical Analysis}

It was calculated that a sample size of 85 cases would be required to observe a $25 \%$ change in the antibiotic prescribing patterns of emergency physicians, with power set at $80 \%$ and using a 2 -sided $\alpha$ of 0.05 . Statistical analysis was performed using SPSS version 17.0.0 (IBM, Armonk, New York). The $\chi^{2}$ test was used to compare categorical data between the pre- and post-intervention groups. In instances where noncategorical data showed evidence of skew, the Mann-Whitney test was used.

\section{RESULTS}

\section{Population}

A total of 171 visits were identified for review during the pre-intervention audit, 7 of which were deemed to not meet the screening criteria. Reasons for exclusion of visits were departure of patient without being seen, no initiation of antibiotic therapy, no diagnosis of UTI, and coding errors (e.g., a diagnosis of gastritis was coded as cystitis due to misinterpretation of handwriting) (see Figure 2).

A total of 147 visits were identified for review during the post-intervention audit, 11 of which did not meet the screening criteria (same reasons for exclusion as in the preintervention audit).

The demographic characteristics of the pre- and postintervention groups were similar, other than classification of UTIs (Table 1): the post-intervention group had significantly more lower UTIs than the pre-intervention group $(p=0.043)$. There was no difference between groups in the utilization of 


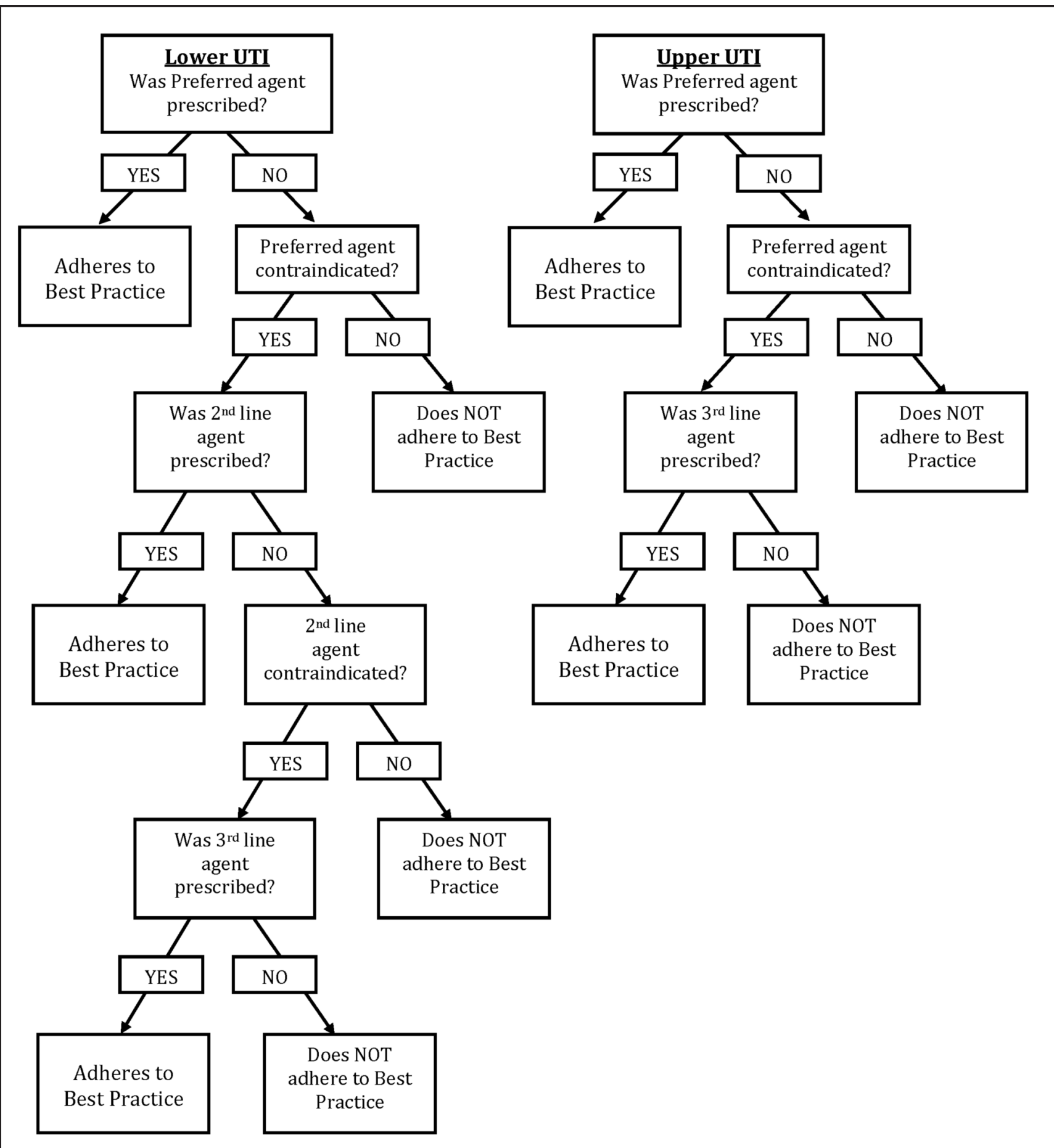

Figure 1. Empiric assessment of best practice for antibiotic treatment of uncomplicated urinary tract infection.

antibiotics traditionally used for the treatment of UTI, namely nitrofurantoin, trimethoprim-sulfamethoxazole (TMP-SMX), and ciprofloxacin (Table 1). The pre-intervention group had a significantly higher rate of previous use of antibiotics in the "other" category $(p=0.007)$, which also drove the higher rate in the overall category $(p=0.038)$. However, these differences are likely not clinically relevant, as the "other" category consisted of antibiotics not traditionally used in the treatment of UTIs (azithromycin, clarithromycin, clindamycin, doxycycline, metronidazole, and cloxacillin). 


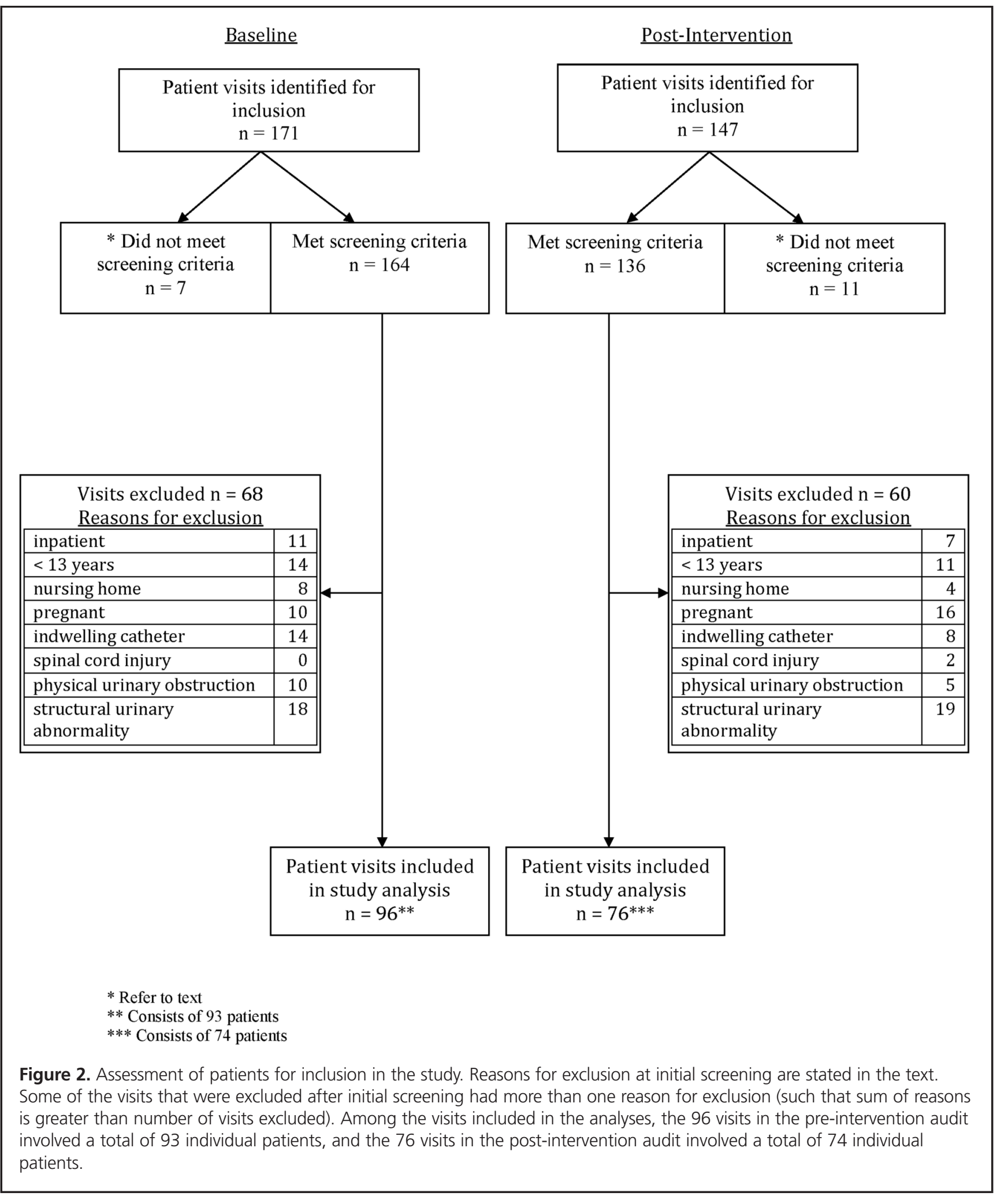


Table 1. Patient Characteristics Before and After Intervention

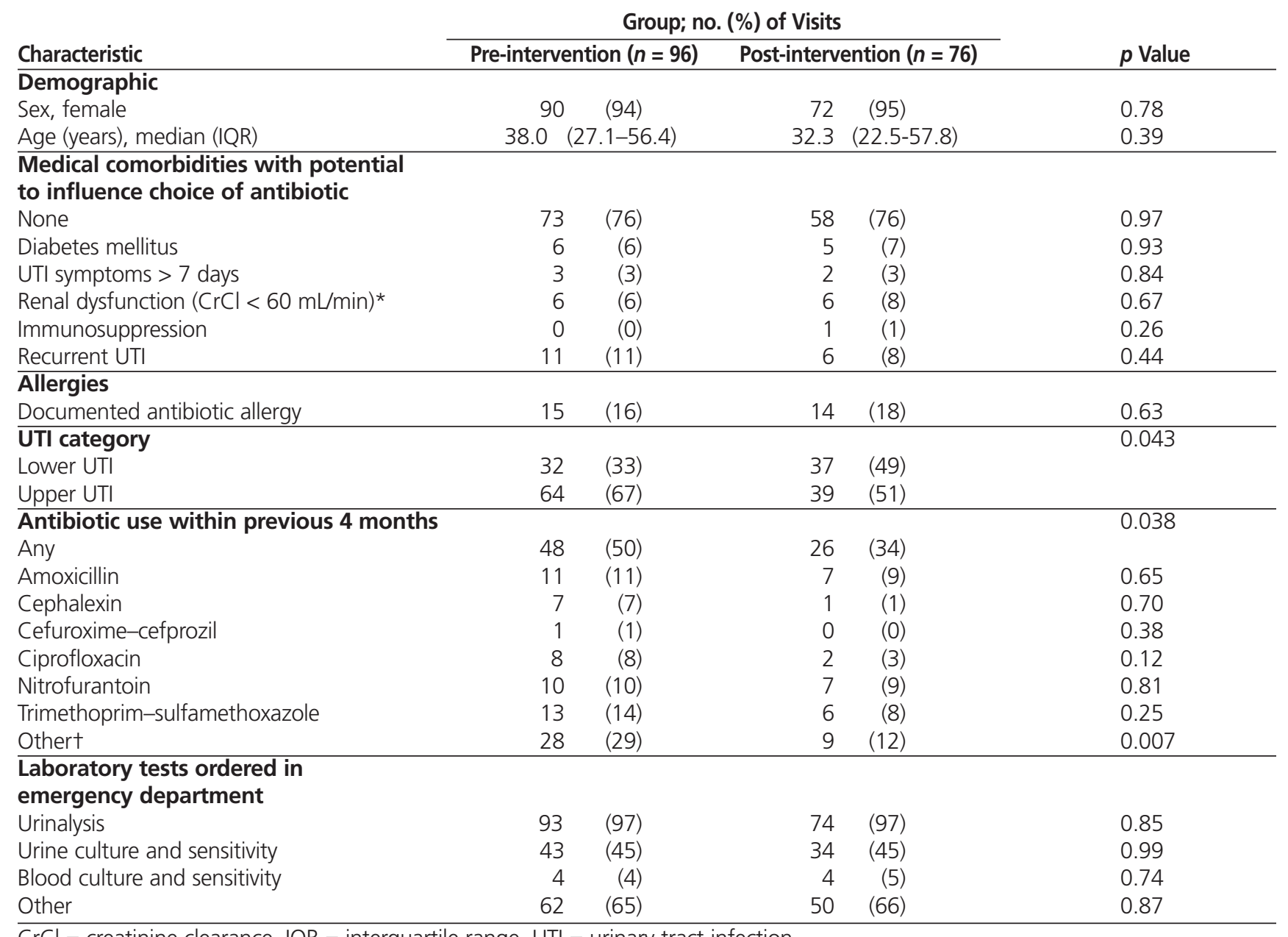

$\mathrm{CrCl}=$ creatinine clearance, $\mathrm{IQR}=$ interquartile range, $\mathrm{UTI}=$ urinary tract infection.

*By modified Cockroft-Gault equation.

†Antibiotics in the "other" category were azithromycin, clarithromycin, clindamycin, doxycycline, metronidazole, and cloxacillin.

\section{Adherence to Best Practice at Pre-intervention Audit}

During the pre-intervention audit period, fewer than half of all empiric orders (39/96 [41\%]) adhered to defined best practice (Table 2). Of the non-adherent orders, the majority (32/57 [56\%]) were for fluoroquinolones, consisting of 31 orders for ciprofloxacin and 1 order for levofloxacin. Ciprofloxacin made up the largest proportion of the 96 prescribed orders (31 [32\%]), followed by nitrofurantoin (29 [30\%]) and TMP-SMX (27 [28\%]) (Table 3).

\section{Adherence to Best Practice at Post-intervention Audit}

During the post-intervention audit period, nearly twothirds of empiric orders (50/76 [66\%]) adhered to defined best practice (Table 2). Nitrofurantoin made up half of all orders (38/76 [50\%]), TMP-SMX accounted for nearly one-third (22/76 [29\%]), and fluoroquinolones accounted for only 9/76
(12\%), 8 of these involving ciprofloxacin (Table 3). Cefuroxime was prescribed in 4 cases (5\%).

\section{Comparison of Pre- and Post-intervention Audits}

There was a significant increase in the proportion of empiric orders that adhered to best practice, from $41 \%$ before the intervention to $66 \%$ after the intervention $(p<0.001)$. This change is believed to have been driven largely by the increase in adherence to best practice in the treatment of lower UTIs $(p=$ 0.021) (Table 2). A $\chi^{2}$ analysis also revealed a significant change in antibiotic selection (odds ratio [OR] 0.25, 95\% confidence interval [CI] 0.11-0.58; $p<0.001)$. Examination of the standardized residuals indicated that this significant change was most likely due to a decrease in ciprofloxacin orders (from 32\% in the pre-intervention period to $11 \%$ in the post-intervention period; see Table 3). There was a corresponding increase in orders for nitrofurantoin, from $30 \%$ to $50 \%$. The proportion 
Table 2. Adherence to Best Practice

\begin{tabular}{|c|c|c|c|}
\hline \multirow[b]{2}{*}{ Type of infection } & \multicolumn{2}{|c|}{ Group; no. (\%) of Visits } & \multirow[b]{2}{*}{$p$ value } \\
\hline & $\begin{array}{c}\text { Pre-intervention } \\
(n=96)\end{array}$ & $\begin{array}{l}\text { Post-intervention } \\
\quad(n=76)\end{array}$ & \\
\hline Lower UTI & $20 / 32 \quad(62)$ & $32 / 37 \quad(86)$ & 0.021 \\
\hline Upper UTI & $19 / 64$ & $18 / 39$ & 0.09 \\
\hline Total & $39 / 96$ & $50 / 76$ & $<0.001 *$ \\
\hline
\end{tabular}

*Odds ratio 2.81, 95\% confidence interval 1.51-5.25.

Table 3. Antibiotic Utilization

Group; no. (\%) of Visits

\begin{tabular}{lrrrr} 
& \multicolumn{3}{c}{ Pre-intervention $(\boldsymbol{n}=\mathbf{9 6})$} & \multicolumn{2}{c}{ Post-intervention $(\boldsymbol{n}=\mathbf{7 6})$} \\
\cline { 2 - 5 } Amoxicillin-clavulanate & 0 & $(0)$ & 1 & $(1)$ \\
Cefuroxime & 0 & $(0)$ & 4 & $(5)$ \\
Ciprofloxacin & 31 & $(32)$ & 8 & $(11)$ \\
Nitrofurantoin & 29 & $(30)$ & 38 & $(50)$ \\
Trimethoprim-sulfamethoxazole & 27 & $(28)$ & 22 & $(29)$ \\
Other & 9 & $(9)$ & 3 & $(4)$
\end{tabular}

of cases treated with TMP-SMX remained unchanged $(28 \%$ and $29 \%$, respectively). Finally, significantly fewer upper UTIs were reported in the post-intervention audit $\left(\chi^{2}=4.16, \mathrm{df}=1\right.$, $p<0.05$; OR 0.53 , 95\% CI 0.28-0.98).

\section{DISCUSSION}

The antimicrobial stewardship initiative described here was successful in significantly improving adherence to best practice in the treatment of uncomplicated UTI, from $41 \%$ before the intervention to $66 \%$ after the intervention. A significant change in antibiotic prescribing practices was also observed, driven largely by a pronounced reduction in ciprofloxacin use, from $32 \%$ to $11 \%$. These successes were achieved through implementation of 2 important antimicrobial stewardship strategies described by the IDSA and SHEA guidelines: education and use of evidence-based practice guidelines.

The criteria for uncomplicated UTI used in this study differed from traditional definitions, ${ }^{7,12,21}$ in that men and postmenopausal women were included in the study population. This approach was used to capture patients whose infection might not fit within the typical definition of uncomplicated UTI but who would typically be treated as such in daily practice at the study institution. The age limit of 13 years was chosen to reflect the reporting practices of the RQHR Microbiology Laboratory for use in the annual antibiogram.

One important limitation of these retrospective chart audits was the classification of UTIs. The vast majority of diagnoses did not specify whether the infection was an upper or lower UTI, but rather indicated a nonspecific UTI. Despite the tactic of inferring diagnoses, 13 patient visits from the preintervention group and 10 visits from the post-intervention group remained unspecified, because none of the expected signs and symptoms were documented. Many of these cases involved patients who presented with some other primary complaint or with vague, constitutional symptoms. These remaining unspecified UTIs were included in the inferred upper UTI group. This reallocation resulted in a statistically significant difference in diagnoses between groups, as there were significantly fewer upper UTIs reported in the postintervention group.

It was apparent that utilization of ciprofloxacin had an impact on adherence to best practice. In the pre-intervention group, ciprofloxacin accounted for 31 (54\%) of the 57 orders that did not meet best practice. The marked decrease in ciprofloxacin use likely played a key role in the statistically significant increase in adherence to best practice, from $41 \%$ to $66 \%$. Despite the overall reduction in ciprofloxacin use, the proportion of cases in which this drug was used for upper and lower UTIs did not appear to change markedly (Table 4). For this reason, it is believed that the utilization of ciprofloxacin decreased independent of the fact that the post-intervention group had a higher rate of lower UTIs.

Analysis of standardized residuals revealed that the increase in nitrofurantoin use (from $30 \%$ to $50 \%$ ) neared statistical significance. This clinically important shift in use of nitrofurantoin is believed to be due to the educational intervention, rather than simply the increased proportion of lower UTIs post-intervention. The educational intervention stressed nitrofurantoin as a first-line agent for lower UTI in the absence of systemic infection or renal failure. This designation was largely related to nitrofurantoin's narrow spectrum of activity, its limited role in cross-resistance, its low cost, and its effectiveness against E. coli in lower UTIs worldwide, despite decades of 
This single copy is for your personal, non-commercial use only.

For permission to reprint multiple copies or to order presentation-ready copies for distribution, contact CJHP at cjhpedit@cshp.ca

Table 4. Antibiotic Use by Diagnosis

Group; No. (\%) of Visits

\begin{tabular}{lcccc}
\cline { 2 - 5 } Antibiotic by Diagnosis & \multicolumn{2}{c}{ Pre-intervention } & \multicolumn{2}{c}{ Post-intervention } \\
\hline Ciprofloxacin & $10 / 31$ & $(32)$ & $3 / 8$ & $(38)$ \\
Lower UTI & $21 / 31$ & $(68)$ & $5 / 8$ & $(62)$ \\
Upper UTI & $12 / 29$ & $(41)$ & $23 / 38$ & $(61)$ \\
Nitrofurantoin & $17 / 29$ & $(59)$ & $15 / 38$ & $(39)$ \\
Lower UTI & & & &
\end{tabular}

$\overline{U T I}=$ urinary tract infection.

utilization. ${ }^{4,7}$ The RQHR antibiogram reflects this effectiveness, as $E$. coli sensitivity was greater than $95 \%$ in $2009 / 2010^{16}$ and $94 \%$ in $2010 / 2011 .^{16,17}$

In the pre-intervention audit period, 17 [59\%] of the 29 nitrofurantoin orders were inappropriately prescribed for upper UTI. This rate of inappropriate prescribing decreased to 15 (39\%) of 38 orders in the post-intervention audit period (Table 4). Notably, all of the nitrofurantoin orders were for inferred upper UTI; given the limitations inherent to chart audits, it is possible that physicians had reasons to suspect lower UTI in these cases but did not document them in the chart. This situation may have resulted in over-inference of upper UTIs, which may in turn have led to overestimation of the number of inappropriate nitrofurantoin orders.

The authors believe that there were 2 key aspects to the success of the intervention undertaken in this study: stakeholder buy-in and availability of quick-reference educational materials. In particular, the study team was fortunate to have the full support of the Director of Emergency Medicine from the inception of the study. This support made it possible to collaborate closely with colleagues in the emergency department. Discussions during the educational intervention were important not only for disseminating defined best practice and understanding the physicians' viewpoint, but also in establishing trust.

Although all of the educational materials were posted on the emergency department's intranet, there was no way to quantify how often they were being accessed. Feedback from physicians after completion of the study indicated that the bestpractice treatment selection tool seemed to be the most-utilized reference, probably because of the strategic locations where it was posted in the emergency department and the visually attractive nature of the poster, which used the green, yellow, and red colours of a stop light (see Appendix 1). Anecdotally, one emergency physician reported that the best-practice treatment selection tool was very well received both by emergency physicians and by general practitioners who passed through the emergency department. For example, several of these general practitioners were known to have made copies of the poster for their own use. Although the current study was not aimed at family physicians, antibiotic prescribing for UTIs certainly represents a common treatment area for which future educational strategies could include general practitioners practising in the community.

\section{Limitations}

This study had several limitations. Interpretation of whether an order followed best practice depended largely on the diagnosis. Given the small number of confirmed diagnoses specifically denoting lower or upper UTI, the diagnosis was inferred for nearly three-quarters of the cases. Because of limitations inherent to a retrospective chart audit, it is possible that the primary investigator's inferences differed from the intent of the treating physician. Thirteen of 30 full-time emergency physicians and 14 casual emergency physicians were not present for the educational intervention, which may have reduced the effect of the intervention. The timeframe for the post-intervention chart audit was disclosed to those in attendance at the educational sessions, so a Hawthorne-type effect may have influenced the results. Because of time constraints, post-intervention data collection occurred shortly after the educational intervention. Therefore, it is not known whether these results will be sustained over the long term. The investigators relied on the Health Information Management Services Department to identify patient visits potentially eligible for inclusion. Given the rate of coding errors discovered during the review, it is possible that some visits were missed.

\section{CONCLUSION}

An educational intervention focused on emergency physicians significantly increased adherence to locally developed best practice and optimized antibiotic prescribing for outpatients with UTIs by limiting overuse of fluoroquinolones, primarily ciprofloxacin. Future interventions may be required to further improve adherence to best practice and to determine what effect this may have on reducing resistance of E. coli to fluoroquinolones.

\section{References}

1. Dellit TH, Owens RC, McGowan JE Jr, Gerding DN, Weinstein RA, Burke JP, et al. Infectious Diseases Society of America and the Society for Healthcare Epidemiology of America guidelines for developing an institu- 
tional program to enhance antimicrobial stewardship. Clin Infect Dis. 2007;44(2):159-77.

2. Zervos MJ, Hershberger E, Nicolau DP, Ritchie DJ, Blackner LK, Coyle $\mathrm{EA}$, et al. Relationship between fluoroquinolone use and changes in susceptibility to fluoroquinolones of selected pathogens in 10 United States teaching hospitals, 1991-2000. Clin Infect Dis. 2003;37(12):1643-8.

3. Practice spotlight: pharmacists in an antimicrobial stewardship program. Can J Hosp Pharm. 2010;63(4):328-9.

4. Nicolle L, Anderson PAM, Conly J, Mainprize TC, Meuser J, Nickel JC, et al. Uncomplicated urinary tract infection in women: current practice and the effect of antibiotic resistance on empiric treatment. Can Fam Physician. 2006;52:612-8.

5. Lautenbach E, Larosa LA, Kasbekar N, Peng HP, Maniglia RJ, Fishman NO. Fluoroquinolone utilization in the emergency departments of academic medical centers: prevalence of, and risk factors for, inappropriate use. Arch Intern Med. 2003;163(5):601-5.

6. Wong-Beringer A, Nguyen LH, Lee M, Shriner KA, Pallares J. An antimicrobial stewardship program with a focus on reducing fluoroquinolone overuse. Pharmacotherapy. 2009;29(6):736-43.

7. Gupta K, Hooton TM, Naber KG, Wullt B, Colgan R, Miller LG, et al. International clinical practice guidelines for the treatment of acute uncomplicated cystitis and pyelonephritis in women: a 2010 update by the Infectious Diseases Society of America and the European Society for Microbiology and Infectious Diseases. Clin Infect Dis. 2011;52(5):e103-20.

8. Weber SG, Gold HS, Hooper DC, Karchmer AW, Carmeli Y. Fluoroquinolones and the risk for methicillin resistant Staphylococcus aureus in hospitalized patients. Emerg Infect Dis. 2003;9(11):1415-22.

9. McCusker ME, Harris AD, Perencevich E, Roghmann MC. Fluoroquinolone use and Clostridium difficile associated diarrhea. Emerg Infect Dis. 2003;9(6):730-3.

10. Hsu DI, Okamoto MP, Murthy R, Wong-Beringer A. Fluoroquinoloneresistant Pseudomonas aeruginosa: risk factors for acquisition and impact on outcomes. J Antimicrob Chemother. 2005;55(4):535-41.

11. Karlowsky JA, Hoban DJ, Decorby MR, Laing NM, Zhanel GG. Fluoroquinolone-resistant urinary isolates of Escherichia coli from outpatients are frequently multidrug resistant: results from the North American Urinary Tract Infection Collaborative Alliance-Quinolone Resistance study. Antimicrob Agents Chemother. 2006;50(6):2251-4.

12. Guay DR. Contemporary management of uncomplicated urinary tract infections. Drugs. 2008;68(9):1169-205.

13. Norris DL 2nd, Young JD. Urinary tract infections: diagnosis and management in the emergency department. Emerg Med Clin North Am. 2008;26(2):413-30, ix.

14. Anti infective Review Panel. Anti infective guidelines for community acquired infections. Toronto (ON): MUMS Guideline Clearinghouse; 2012.

15. Guneysel O, Onur O, Erdede M, Denizbasi A.Trimethoprim/ sulfamethoxazole resistance in urinary tract infections. J Emerg Med. 2009;36(4):338-41.

16. RQHR antibiogram 2009/2010. Regina (SK): Regina Qu'Appelle Health Region; 2010.

17. RQHR antibiogram 2010/2011. Regina (SK): Regina Qu'Appelle Health Region; 2011.

18. Marr JJ, Moffet HL, Kunin CM. Guidelines for improving the use of antimicrobial agents in hospitals: a statement by the Infectious Diseases Society of America. J Infect Dis. 1988;157(5):869-76.

19. Shlaes DM, Gerding DN, John JF Jr, Craig WA, Bornstein DL, Duncan RA, et al. Society for Healthcare Epidemiology of America and Infectious Diseases Society of America Joint Committee on the Prevention of Antimicrobial Resistance: guidelines for the prevention of antimicrobial resistance in hospitals. Clin Infect Dis. 1997;25(3):584-99.
20. Canadian hospital pharmacy 2015 (CSHP 2015) goals and objectives. Ottawa (ON): Canadian Society of Hospital Pharmacists; 2011 [cited 2012 Feb 11]. Available from: www.cshp.ca/dms/dmsView/2_CSHP2015-Goals-and-Objectives-Feb-25\%2707-w-Appdx-rev-May\%2708.pdf

21. Nicolle L; AMMI Canada Guidelines Committee. Complicated urinary tract infection in adults. Can J Infect Dis Med Microbiol. 2005;16(6):349-60.

Eric Landry, BSP, ACPR, was, at the time of this study, a pharmacy practice resident (2011/2012) with the Regina Qu'Appelle Health Region, Regina, Saskatchewan, and completed this project in partial fulfillment of the residency requirements. He is currently with the College of Pharmacy and Nutrition at the University of Saskatchewan, Saskatoon, Saskatchewan, as Coordinator of the Medication Assessment Centre.

Linda Sulz, BSP, PharmD, is with the Regina Qu'Appelle Health Region, Regina, Saskatchewan.

Ali Bell, MA, MSc, is with the Regina Qu'Appelle Health Region, Regina, Saskatchewan.

Lane Rathgeber, BSC, MD, CCFP(EM), is with the Regina Qu'Appelle Health Region, Regina, Saskatchewan.

Heather Balogh, BSP, is with the Regina Qu'Appelle Health Region, Regina, Saskatchewan.

Competing interests: Eric Landry was the Saskatchewan representative on the CSHP 2015 Branch Champion subcommittee. Linda Sulz is Chair of the Regina Qu'Appelle Health Region Antimicrobial Stewardship Program (formerly the Antimicrobial Utilization Committee). She has also received reimbursement from Janssen and Gilead for expenses related to advisory board meetings; reimbursement from Janssen, Merck, and Sunovion for conference attendance; and honoraria from Pfizer, Sanofi, and Merck for a "Train the Trainer" webinar and for continuing education presentations. No other competing interests declared.

\section{Address correspondence to:}

Eric Landry

College of Pharmacy and Nutrition

University of Saskatchewan

Health Sciences Bldg, E-wing, Rm 3204

104 Clinic Place

Saskatoon SK S7N 5E5

e-mail: e.landry@usask.ca

\section{Acknowledgements}

The authors thank Dr. Francis Bowen (Head, Emergency Department, Regina Qu'Appelle Health Region), Dr. Kumudhini Karunakaran (Infectious Diseases Specialist), and Dr. Johan Delport (Medical Microbiologist) for their contributions and support of the study; Patty Chesters, Kim Fichter (Health Records Analysts), and Margaret Velestuk (Laboratory Information Technologist) for their assistance with data management; Corey Herod (Pharmacy Information Technologist) for information technology support; and William Semchuk, Casey Phillips, and Suzanne Gulka (members of the UTILISE Advisory Committee) for their contributions to idea generation and study development. 